\title{
Exclusivity and Exclusion on Platform Markets*
}

\author{
Subhasish M. Chowdhury \\ University of East Anglia \\ s.modak-chowdhury@uea.ac.uk
}

\author{
Stephen Martin ${ }^{\dagger}$ \\ Purdue University \\ smartin@purdue.edu
}

June 2016

\begin{abstract}
We examine conditions under which an exclusive license granted by the upstream producer of a component that some consumers regard as essential to one of two potential suppliers of a downstream platform market can make the unlicensed supplier unprofitable, although both firms would be profitable if both were licensed. If downstream varieties are close substitutes, an exclusive license need not be exclusionary. If downstream varieties are highly differentiated, an exclusive license is exclusionary, but it is not in the interest of the upstream firm to grant an exclusive license. For intermediate levels of product differentiation, an exclusive license is exclusionary and maximizes the upstream firm's payoff.

Keywords: exclusion; essential components; exclusive contract; platform market.

JEL codes: L12, L13, L22

${ }^{*}$ We thank Ralph Siebert, Dries De Smet, seminar participants at the IUPU - Indianapolis, Purdue University, the University of East Anglia, the Korea Institute of Industrial Economics and Trade, the University of Louisville, participants at the ZEW Conference on Platform Markets, Mannheim, and three anonymous referees for useful comments. Responsibility for errors is our own.

$\dagger$ Corresponding author.
\end{abstract}




\section{Introduction}

We model a platform market that is supplied by an upstream firm with a complementary good that some consumers on one side of the market regard as essential. The model is a stylized version of a newspaper market, potentially a duopoly. Downstream firms are differentiated platforms, newspapers, that supply the two sides, advertisers and readers, of the platform market. The upstream firm, a syndicate, is the monopoly supplier of publishable material - newspaper columns and comic strips. We show that the impact of an exclusive license granted by the upstream firm to one of the downstream firms depends on the extent of differentiation between the products of the downstream firms and on the relative size of the market segment that regards the complementary good as essential. If consumers regard downstream varieties as close substitutes, duopoly with only one firm licensed to publish the complementary material can be an equilibrium outcome. For intermediate degrees of product differentiation and a sufficiently large fraction of the population that regards the complementary good as essential, an exclusive license can deprive the unlicensed firm of enough advertising revenue to make it unprofitable. For high levels of product differentiation, an exclusive license would make an unlicensed newspaper unprofitable, but the payoff-maximizing choice for the upstream firm is to license both firms.

In a platform market, two groups of users interact through a platform firm. The benefit to users on one side of the market increases with the number of users on the other side of the market, and a platform is able to charge individual prices to the two groups (Rochet and Tirole, 2006). The newspaper industry is a prototypical example of a platform market. It involves three sets of players: newspapers, readers, and advertisers. In this perspective, readers and advertisers are the two user groups that interact on newspaper platforms.

A newspaper commonly publishes features (articles, comics, puzzles, etc.), along with local, national, and international news and advertisements. Newspaper employees prepare some published material; the remainder is purchased from press syndicates. Press syndicates are upstream firms that sell specialized material to newspapers. Some such syndicates specialize in the distribution of comic strips, acting as agents for cartoonists, often under exclusive contracts.

An episode from the Dallas, Texas newspaper market exemplifies the phe- 
nomenon we model. ${ }^{1}$ On August 2, 1989, the Dallas Morning News ('Morning News') signed an exclusive contract for 26 columns and comic strips provided by the Universal Press Syndicate. Until the signing of the exclusive contract, the material had been available through the Dallas Times Herald ('Times Herald'). The two newspapers had competed in the Dallas area for more than a century. The Universal Syndicate acknowledged that the move was 'predatory', but said that denial of the material was required by its contract with the Morning News. The Times Herald suffered a circulation loss of 9,000 to 10,000 weekday and 15,000 Sunday deliveries. It filed an antitrust lawsuit asking for $\$ 33$ million in actual damages and up to three times that amount in punitive damages against the Morning News and its parent company.

A state judge in Texas refused to grant the Times Herald a preliminary injunction to prevent the movement of the syndicated features, on the ground that the Times Herald could publish substitute features supplied by competing syndicates. The Times Herald subsequently lost a District Court jury trial and an appeal of the District Court outcome. The Morning News nonetheless paid $\$ 1.5$ million to the Times Herald as part of an outside settlement. The Times Herald was unable to recapture its lost reader base and advertising revenue. The Morning News' parent corporation purchased the Times Herald on December 8, 1991 and stopped its publication the next day. ${ }^{2}$

Although we focus specifically on the newspaper market in the current study, other platform markets can also portray similar situations of exclusivity. An example of such from the U.S. television industry involves Project Runway, a reality show based on fashion design that was shown by the Bravo Network from 2004 to 2008. On July 2006 the show's producers made an exclusive deal to move the show to Lifetime Television starting from 2009. Litigation followed, and was privately settled after Bravo Network prevailed

\footnotetext{
${ }^{1}$ See the Appeals Court decision in Times Herald Printing Co. v. A. H. Belo Corporation et al. (Court of Appeals of Texas, Fourteenth District) 820 S.W.2d 206; 1991 Tex. App. LEXIS 2899; 335-66 Trade Cas. (CCH) P69, 680 (1991). Also see Gelsanliter (1995).

${ }^{2}$ The rise of the internet has made print media a declining industry. (The general increase in concentration in the newspaper markets of US cities, and the corresponding reasons and consequences are discussed in Bucklin et al. (1989) and Genesove (2003).) Our stylized model is not meant to imply that the Morning News' exclusive arrangement with the United Press Syndicate was the unique factor responsible for the demise of the Times Herald. But the fact that the Times Herald's otherwise unsuccessful legal action resulted in a $\$ 1.5$ million private settlement is consistent with the view that the exclusive arrangement was a contributing factor in the demise.
} 
in early stages. In 2009, Bravo Network launched a competing program ("The Fashion Show"), which enjoyed about one-quarter Project Runway's number of viewers, and correspondingly less advertising revenue. The Fashion Show broadcast its last episode on 25 January $2011 .{ }^{3}$

The results of the current study contribute to two literatures. First, it broadens our understanding of the nature of strategic interactions in imperfectly competitive platform markets. Second, it contributes to the literature on exclusion by considering the effect of an exclusive license for a complementary good in a platform market.

The rest of the paper is organized as follows. In Section 2 we review the parts of the literature on exclusionary contracts involving complementary goods that are most closely related to the present study. Section 3 contains the setup of the model. In Section 4, we present results for the monopoly case. Section 5 contains the basic duopoly model. Section 6 discusses equilibrium licensing behavior for moderately differentiated newspapers. Section 7 contrasts the outcome for an intermediate degree of product differentiation with outcomes if product differentiation is either low or high. Section 8 concludes. ${ }^{4}$

\section{$2 \quad$ Literature Review ${ }^{5}$}

The issue of exclusion and complementary components is discussed in the empirical literature. Dewenter (2003) shows that newspapers, among other media, can form consumer habits that translate into demand for a commodity that becomes an essential component of the media product. Argentesi (2004) shows empirically that weekly supplements (comics, puzzles, etc.) increase

\footnotetext{
${ }^{3}$ See Huff, Richard "Project Runway' quits Bravo for Lifetime," NYDailyNews.com 7 April 2008; Lafayette, Jon "NBCU wins round in 'Project Runway'," TVWeek.com, 26 September 2008; Associated Press, "Project Runway' is cleared for move to Lifetime from Bravo," 1 April 2009. For a further example of an exclusionary strategy based on loss of advertising revenue in a platform market, see Lorain Journal Co. v. United States, 342 U.S. 143 (1951). Similarly, T-Mobile's failure to obtain the right to sell Apple iPhones was mentioned as a factor in its proposed March 2011 takeover by AT\&T. Other examples are provided by "killer apps" available only on a single platform; see Viecens (2009).

${ }^{4}$ Full details of proofs are contained in an appendix that is available on request from the authors.

${ }^{5}$ See Rysman (2009) and Whinston (2006, Chapter 4) for surveys of platform markets and exclusionary vertical contracts, respectively.
} 
readership of (and as a result advertisement in) newspapers. If a newspaper is denied the possibility of supplying habit-forming content, the newspaper will see its reader base, and with it advertising revenue, decline. This loss of revenue from one side of the market because of reduced patronage on the other side is central to the exclusionary impact of an exclusive license in a platform market. ${ }^{6}$

In the theoretical literature, the issue of exclusion manifests itself in different ways when modeling different industries. Church and Gandal (2005) argue that directly denying or restricting compatibility among complementary products is exclusionary in the telecommunications industry. ${ }^{7}$ Hagiu and Lee (2011) discuss the incentives of content providers to enter into exclusive as opposed to non-exclusive contracts with platforms (such as TV channels). ${ }^{8}$ Their model has much in common with ours: downstream firms are platforms; end users (readers, in our model) single home. But there is no essential complementary good in Hagiu and Lee (2011), and the nature of their results hinges on whether or not the content provider controls its own pricing to end users. Direct control of pricing does not arise in newspaper markets, which we use as our prototype. In our model, it is the degree of product differentiation in the downstream market that determines if the upstream firm offers an exclusive license for its content.

Hogendorn and Yuen (2009) develop a model that can be thought of as a stylized version of a video game console duopoly. User utility from a platform rises with the number of components on the platform. Components developed for one platform can be ported to the other, at a cost. A content provider offers a "must-have" component that provides additional utility. Each console has an installed base of locked-in users. Whereas Hogendorn and Yuen limit attention to parameter values for which exclusion of one platform ("tipping") does not occur, we explore conditions under which an exclusive license for an essential complementary good results in exclusion. The components of the Hogendorn and Yuen model correspond to advertisements in the Armstrong (2006) model that we extend. There is no equivalent of porting in this framework since readers are not locked-in in

\footnotetext{
${ }^{6}$ We incorporate this effect in our model by assuming that a fraction $\mu$ of the reader side of the market will read a newspaper, if at all, only if it includes an essential complementary good, as further discussed in Section 3.2.

${ }^{7}$ See also the remarks of Rey and Tirole (2007, p. 2205).

${ }^{8}$ See also Stennek (2014), Weeds (2015).
} 
the Hotelling framework. ${ }^{9}$

Doganoglu and Wright (2010) model agreements by agents on one side of a platform to supply only one platform firm. Their basic model is of a one-sided market. Our model examines conditions under which an upstream firm will offer an exclusive license to one platform firm. The Doganoglu and Wright model does not involve essential components, either in the sense of Hogendorn and Yuen (2009) or in the sense of the model developed here.

\section{Setup}

We modify the Armstrong (2006) "competitive bottlenecks" model (Armstrong, 2006, p. 679): "Here, if it wishes to interact with an agent on the single-homing side, the multi-homing side has no choice but to deal with that agent's chosen platform. Thus, platforms have monopoly power over providing access to their single-homing customers for the multi-homing side." The two sides of the platform market are comprised of readers and advertisers, respectively.

We assume that readers single-home, reading at most one newspaper. ${ }^{10}$ Differences in reader taste and preference are captured by one of the standard models of horizontal product differentiation, the Hotelling main street model. If both firms enter, there are two newspapers, ' $\mathrm{A}$ ' located at the left end and ' $\mathrm{B}$ ' located at the right end of a Hotelling line of length 1 . Newspapers sell advertising space to advertisers and print copies of newspapers for sale to readers. There is a syndicate that sells copyrighted materials, such as cartoons and comics, to the newspapers. We normalize the mass of potential

\footnotetext{
${ }^{9}$ Lee (2013) analyzes the impact of vertical integration and exclusivity on the sixth generation of the U.S. video game industry. He finds that exclusive contracts facilitated entry, but notes that this is not a necessary outcome (p. 2962): "although certain exclusive titles on the incumbent platform sold more copies than any title on the entrant platforms, estimates indicate that these titles did not influence hardware demand as much as those onboard the entrants. If it were the case that the most valuable software products were exclusive to the incumbent in the data, then the predictions of the counterfactual would have been reversed." Shapiro (1999, p. 676) ascribes exclusionary effects to exclusive contracts entered into by the Nintendo Entertainment System.

${ }^{10}$ Rysman (2007) documents that credit-card users concentrate purchases on one credit card, in effect single-homing, while holding infrequently-used credit cards in reserve. In the same way, one may take the assumption of single-homing newspaper readers as approximating the conduct of users who read primarily one newspaper, while occasionally looking at other newspapers.
} 
readers and the mass of potential advertisers to be 1 . Readers are uniformly distributed along the Hotelling line and incur "transportation cost" $t$ per unit distance to the chosen end of the line in reading a newspaper. ${ }^{11} n_{R}^{i}$ denotes the number of readers of newspaper $i$, and $n_{a}^{i}$ denotes the number of firms that advertise in newspaper $i .^{12}$

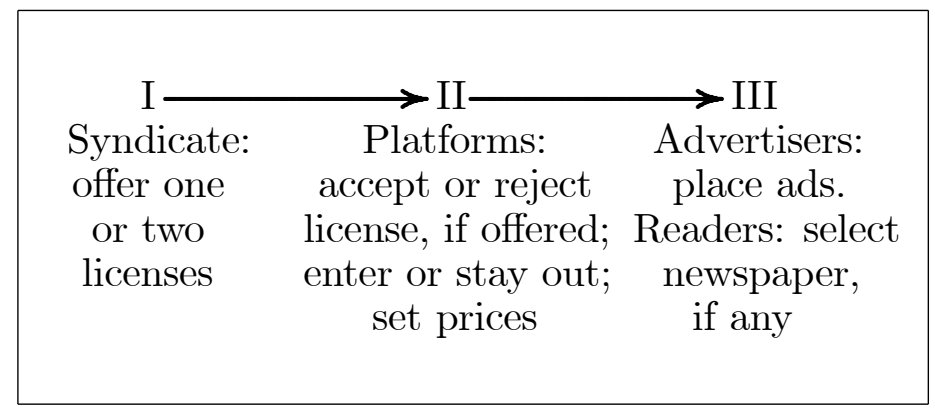

Figure 1: Sequence of decisions.

We model the incentive of the syndicate to offer an exclusive license and the incentive of a newspaper to accept a license, exclusive or not, if offered. We investigate Nash equilibrium outcomes.

The three stages of the game are shown in Figure 1. We treat the syndicate's costs as being entirely sunk before it interacts with newspapers. ${ }^{13}$ In stage I, the syndicate makes a take-it-or-leave-it offer of a license to publish the complementary material to either one (without loss of generality, to firm A) or both newspapers. ${ }^{14}$ In stage II, if a newspaper is offered a license, it decides among three options: (i) accept the license and enter the market, (ii) reject the license and enter the market, or (iii) stay out of the market. If a newspaper is not offered a license, it decides either to enter the market or

\footnotetext{
${ }^{11}$ In the context of newspaper markets, preferences might relate to the ideological position of a newspaper's editorial page. Alternatively, preferences might represent the time of day at which a reader would prefer to receive a newspaper; in practice, the alternatives are morning and evening.

${ }^{12}$ In what follows, unless otherwise noted, references to "newspaper $i$ " should be understood to carry the qualification "for $i=A, B$."

${ }^{13}$ It would be possible to model the syndicate's arrangements with the authors of the material it markets; this would take us far afield from our topic.

${ }^{14}$ In principle, one might include a third option, not to offer a license to either newspaper. The syndicate's payoff for this option is zero economic profit, it would not be a profitmaximizing choice, and we eliminate it for simplicity.
} 
to stay out. ${ }^{15}$ Newspapers that enter set advertising rates and newspaper prices. In the final stage, advertisers place advertisements and readers select newspapers.

The terms on which the syndicate offers a license determine the division of economic profit between the syndicate and a platform that accepts the offer of a license. Market outcomes under alternative licensing arrangements determine the magnitude of the rents that are divided between syndicate and platforms.

\subsection{Advertisers}

Let $\gamma^{i}$ denote newspaper $i$ 's per-reader advertising rate. ${ }^{16}$ The cost of placing an advertisement in newspaper $i$ is

$$
\gamma^{i} n_{R}^{i}
$$

Advertisers differ in their profit per sale, $\beta$. Following Armstrong (2006), we assume that newspapers do not observe the $\beta$ of any particular advertiser, but know the distribution of $\beta$ in the population of advertisers. We assume $\beta$ is uniformly distributed in the interval $[0,1]$. Given this distribution, it will be profitable for an advertiser to place an advertisement in newspaper $i$ if the profit from placing the advertisement is greater than or equal to the cost of placing the advertisement, $\beta n_{R}^{i} \geq \gamma^{i} n_{R}^{i}$. The expected number of advertisements demanded from newspaper $i$ is therefore

$$
n_{a}^{i}=1-\gamma^{i}
$$

\subsection{Readers}

\subsubsection{No Essential Component}

If there is no essential complementary good, the net utility of a reader of newspaper $i$, before allowing for transportation cost $t$ is

$$
u_{R}^{i}=\alpha n_{a}^{i}-p^{i}
$$

\footnotetext{
15 "Staying out of the market" means the newspaper can earn a normal rate of return on investment elsewhere.

${ }^{16}$ See Rosse (1970) for an estimation of advertising cost in newspaper and Armstrong (2006) for discussion of the case in which the price of placing an advertisement is not proportional to the number of readers.
} 
where $\alpha$ is marginal utility per advertisement. ${ }^{17}$

As noted above, we assume readers single-home. For a reader located at $x$ on the Hotelling line, net utilities are

$$
u_{R}^{A}-t x
$$

from newspaper A,

$$
u_{R}^{B}-t(1-x)
$$

from newspaper B.

If the market is covered, ${ }^{18}$ boundary readers are at a location that yields the same net utility from either newspaper, leading to boundary location

$$
n_{R}^{A}=x^{*}=\frac{1}{2}+\frac{u_{R}^{A}-u_{R}^{B}}{2 t}=\frac{1}{2}+\frac{\alpha n_{a}^{A}-p^{A}-\left(\alpha n_{a}^{B}-p^{B}\right)}{2 t} .
$$

The number of readers of each newspaper are

$$
\begin{aligned}
& n_{R}^{A}=\frac{1}{2}+\frac{\alpha\left(n_{a}^{A}-n_{a}^{B}\right)-p^{A}+p^{B}}{2 t} \\
& n_{R}^{B}=\frac{1}{2}+\frac{\alpha\left(n_{a}^{B}-n_{a}^{A}\right)-p^{B}+p^{A}}{2 t} .
\end{aligned}
$$

\subsubsection{Essential Complementary Good}

If some portion $\mu$ of the population regards comics as an essential complementary good, we assume that the specification of readers' demand in equations (3) and (4) describes the preferences of the fraction $1-\mu$ of the population, for $0 \leq \mu \leq 1$, that does not regard comics as essential. Then quantities demanded of each newspaper from this part of the population are

\footnotetext{
${ }^{17}$ We follow Armstrong (2006) and model advertisements as information-containing messages that are valued by consumers. This specification makes explicit the reason businesses find it profitable to advertise: by informing readers of a purchase opportunity, advertisers increase sales. An alternative specification would treat advertisements as bads rather than goods; see Kind et al. (2006) for a model of the television market along these lines. In this formulation, even though advertisements reduce readers' utility, they are profitable for firms.

${ }^{18}$ Equation (18), Section 5.1, gives the maximum value of $t$ for the market to be covered in low- $t$ duopoly if both newspapers are licensed to publish the essential complementary material.
} 
$1-\mu$ times the numbers of readers given by (3) and (4), from platforms A and $\mathrm{B}$ respectively.

We assume that the remaining portion $\mu$ of the population will read only a newspaper that publishes comics. Otherwise, the utility of this group of consumers is as above. That is, for a consumer who regards comics as an essential component of a newspaper, comics yield no utility in and of themselves, but are a prerequisite for getting utility from a newspaper. This specification minimizes the exclusionary effect of an exclusive license to print comics. ${ }^{19}$ A consumer who regards comics as an essential component of a newspaper purchases a newspaper only if it contains comics and if the net utility from reading the newspaper, allowing for transportation cost, is nonnegative.

Suppose newspaper A has an exclusive license to publish comics. The most-distant reader from the "comics" group who reads newspaper A is at the right end of the line if (recall the length of the line is 1) $u_{R}^{A}-t=$ $\alpha n_{a}^{A}-p^{A}-t \geq 0$, or equivalently if $p^{A}$ is sufficiently low,

$$
p^{A} \leq \alpha n_{a}^{A}-t .
$$

On the other hand, if

$$
p^{A}>\alpha n_{a}^{A}-t,
$$

the most distant reader from the "comics" group who reads newspaper A is at the distance that makes net utility zero, $x_{\mu}=\left(\alpha n_{a}^{A}-p^{A}\right) / t$.

Quantities demanded of the two newspapers are

$$
\begin{array}{r}
n_{R}^{A}=(1-\mu)\left[\frac{1}{2}+\frac{\alpha\left(n_{a}^{A}-n_{a}^{B}\right)-p^{A}+p^{B}}{2 t}\right] \\
\quad+\mu\left\{\begin{array}{ll}
1 & p^{A} \leq \alpha n_{a}^{A}-t \\
\frac{\alpha n_{a}^{A}-p^{A}}{t} & p^{A}>\alpha n_{a}^{A}-t
\end{array}\right] \\
n_{R}^{B}=(1-\mu)\left[\begin{array}{ll}
\frac{1}{2}+\frac{\alpha\left(n_{a}^{B}-n_{a}^{A}\right)-p^{B}+p^{A}}{2 t}
\end{array}\right] .
\end{array}
$$

The number of readers for a newspaper with an exclusive license differs depending on whether price is low (all consumers who regard comics as essential read the licensed newspaper) or high (consumers who regard comics as essential and who are distant from the licensed newspaper do not read any newspaper).

\footnotetext{
${ }^{19}$ See the discussion in Section 2 of Hogendorn and Yuen (2009).
} 


\subsection{Platforms}

The cost of producing one issue of a newspaper that contains $n_{a}$ advertisements is

$$
f+c n_{a} .
$$

$f$ is the part of the cost of printing a newspaper that is fixed with respect to the number of advertisements. $c$ is the constant marginal cost per advertisement per issue. $c n_{a}$ is marginal cost. The newspaper's overall fixed cost is $F .^{20}$

Let

$$
\pi_{R}^{i}=p^{i}+\left(\gamma^{i}-c\right)\left(1-\gamma^{i}\right)-f
$$

denote newspaper $i$ 's profit per reader - revenue $p^{i}$ on the sale of the newspaper to the reader, $\gamma^{i}-c$ gross profit per reader per advertisement placed, $n_{a}^{i}=1-\gamma^{i}$ advertisements placed, minus $f$.

Newspaper $i$ 's profit maximization problem is

$$
\max _{p^{i}, \gamma^{i}} n_{R}^{i} \pi_{R}^{i}-F
$$

\section{A Monopoly Platform}

We examine monopoly equilibrium both to build intuition and because if an exclusive license makes it unprofitable for one newspaper to operate, it is monopoly profit that is divided between the licensed newspaper and the syndicate.

Suppose there is only one platform, newspaper A. If newspaper A is a monopoly supplier, the net utility of a reader located at $x$ is

$$
u_{R}^{A}=\alpha\left(1-\gamma^{A}\right)-p^{A}-t x .
$$

If the monopoly newspaper has a license for the essential complementary good, its number of readers is

$$
n_{R}^{A}=\left\{\begin{array}{cl}
1 & p^{A} \leq \alpha\left(1-\gamma^{A}\right)-t \\
\frac{\alpha\left(1-\gamma^{A}\right)-p^{A}}{t} & p^{A} \geq \alpha\left(1-\gamma^{A}\right)-t
\end{array} .\right.
$$

\footnotetext{
${ }^{20}$ The fixed cost of gathering news to produce the first copy of the paper is typically high, the variable cost to print and sell additional copies of newspaper low. See Rosse (1970) and Strömberg (2004) for estimation and interpretation of cost structures in the newspaper market.
} 
If the monopoly newspaper does not have a license for the essential complementary good, the expressions for the number of readers in (9) are scaled down by a factor $1-\mu$.

\subsection{Low price (low $t$ )}

In the low-price case, the market is covered. Newspaper A's problem is

$$
\max _{p^{A}, \gamma^{A}} n_{R}^{A} \pi_{R}^{A}-F
$$

such that

$$
p^{A} \leq \alpha\left(1-\gamma^{A}\right)-t
$$

(which gives $n_{R}^{A}=1$ ).

Intuitively (and this can be verified formally), for newspaper A to maximize profit in the low-price case, the constraint must be binding for the most distant reader,

$$
p_{A}=\alpha\left(1-\gamma^{A}\right)-t \equiv p_{\text {low } t}^{m *} .
$$

It cannot be optimal for newspaper A to leave the most distant consumer with any surplus.

Given (10), newspaper A's problem can be reformulated as

$$
\max _{\gamma^{A}}\left(1-\gamma^{A}\right)\left(\alpha+\gamma^{A}-c\right)-t-f-F .
$$

The first-order condition to solve (11) is

$$
\left(1-\gamma^{A}\right)-\left(\alpha+\gamma^{A}-c\right) \equiv 0 \text {. }
$$

A marginal increase in $\gamma^{A}$ reduces the number of advertisements sold, $1-\gamma^{A}$, but increases profit per advertisement, $\alpha+\gamma^{A}-c$. Part of the change in profit per advertisement is the decrease in the price readers pay, (10). Part of the increase in profit per advertisement is the increase in profit from sales to advertisers, $\gamma^{A}-c$.

From (12), the monopoly price per reader of an advertisement is

$$
\gamma^{A}=\frac{1}{2}[1-(\alpha-c)] \equiv \gamma^{*}
$$

Because $\gamma$ is the equilibrium price per reader per advertisement, the firstorder condition that determines $\gamma$, and the resulting equilibrium value, is 


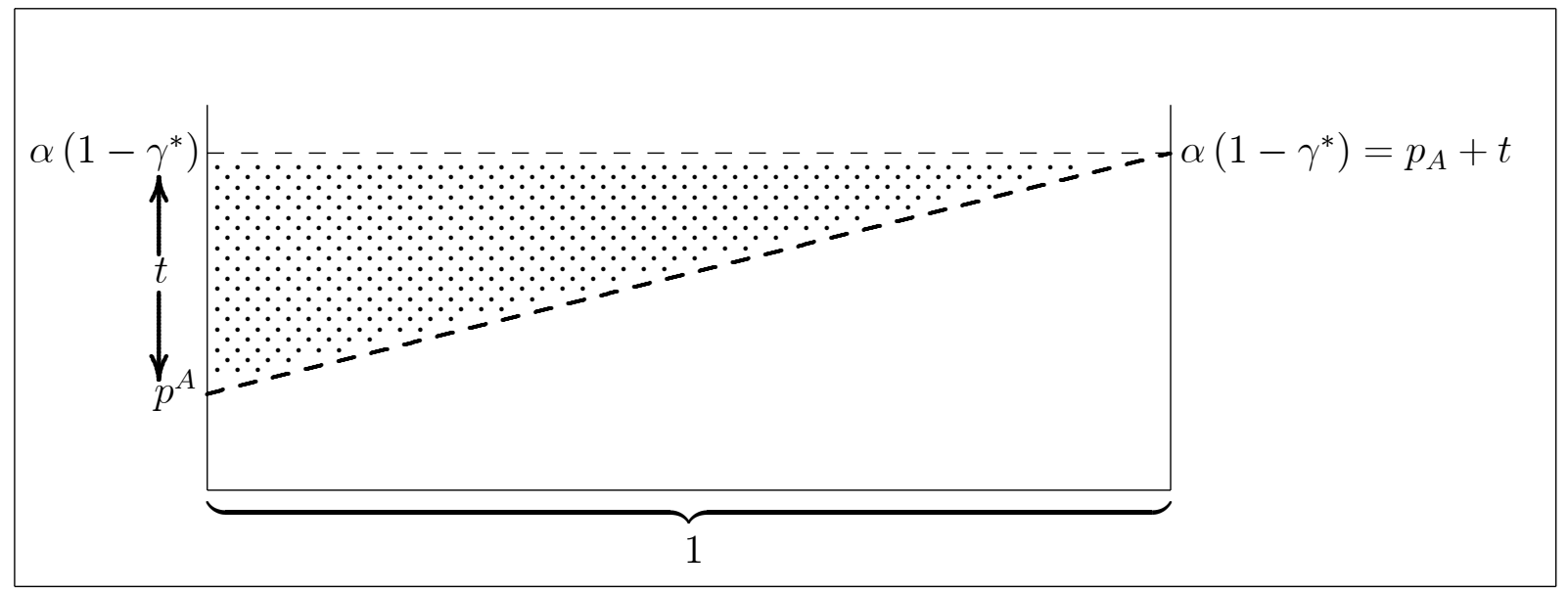

Figure 2: Monopoly pricing, low- $t$ regime. Shaded area is consumer surplus. The horizontal axis shows location on the Hotelling line. The vertical axis shows delivered price.

the same, $\gamma^{*}$, for all newspapers in all models considered in this paper. This is the "competitive bottleneck" aspect of the basic model: depending on the details (monopoly, duopoly, essential complementary good), a platform's equilibrium number of readers will vary. But it is a monopolist with respect to those readers' access to advertisements, and it charges advertisers the monopoly price.

The low- $t$ monopoly outcome is illustrated in Figure 2.

\subsection{High price (high $t$ )}

In the high-price regime, newspaper A's problem is

$$
\max _{p^{A}, \gamma^{A}} n_{R}^{A} \pi_{R}^{A}-F
$$

such that $p^{A} \geq \alpha\left(1-\gamma^{A}\right)-t$. The monopoly price per reader of an advertisement is again $\gamma^{*}$, and the monopoly price is

$$
p_{\text {high } t}^{m *}=\frac{1}{2}\left[\left(\alpha+c-\gamma^{*}\right)\left(1-\gamma^{*}\right)+f\right] .
$$

A consistency condition for this solution to be valid is $p_{\text {high } t}^{m *} \geq \alpha\left(1-\gamma^{A}\right)-$ $t$. On some rearrangement of terms, the consistency condition for the high- 


\begin{tabular}{|l|c|c|}
\hline & $t \leq t_{H}$ & $t>t_{H}$ \\
\hline Licensed & $2 t_{H}-t-F$ & $\frac{t_{H}^{2}}{t}-F$ \\
\hline Unlicensed & $(1-\mu)\left(2 t_{H}-t\right)-F$ & $(1-\mu) \frac{t_{H}^{2}}{t}-F$ \\
\hline
\end{tabular}

Table 1: Monopoly payoffs.

price solution to apply is that transportation cost be sufficiently high,

$$
t>\frac{1}{2}\left[\left(1-\gamma^{*}\right)^{2}-f\right] \text {. }
$$

In the contrary case,

$$
t \leq \frac{1}{2}\left[\left(1-\gamma^{*}\right)^{2}-f\right]
$$

it is the low-price solution that maximizes monopoly profit.

The threshold value of transportation cost, which should be given its figurative interpretation as an indicator of the extent of product differentiation, appears repeatedly in what follows, and for notational compactness we define

$$
t_{H} \equiv \frac{1}{2}\left[\left(1-\gamma^{*}\right)^{2}-f\right] \text {. }
$$

\subsection{Monopoly Payoffs}

For low levels of transportation cost, $t \leq t_{H}$, a monopoly supplier sets price so the market is covered, extracting all surplus from the most distant readers. For higher levels of transportation cost, the market is not covered. Row 1 of Table 1 gives the equilibrium payoff of a monopoly newspaper if the newspaper is licensed (all readers are in the market, although not all readers may be served). Row 2 of Table 1 gives the equilibrium payoffs of an unlicensed monopolist.

In what follows, we assume parameter values such that licensed monopoly is profitable. From the second row, an unlicensed monopoly is unprofitable for $\mu$ sufficiently close to 1 .

\section{Newspaper Duopoly}

Expression (8) is the generic form of the duopoly maximization problem. The relation between the number of readers and prices differs depending on 
whether both newspapers are licensed, one newspaper is licensed, or neither newspaper is licensed.

\subsection{Both newspapers licensed}

As noted above (see remarks immediately after (12)), the equilibrium price per reader of an advertisement is $\gamma^{*}=\frac{1}{2}[1-(\alpha-c)]$. If both newspapers are licensed and the market is covered, equilibrium prices to readers are

$$
p^{A}=p^{B}=t-\left[\left(1-\gamma^{*}\right)\left(\gamma^{*}-c\right)-f\right] .
$$

The market is covered at these prices, as we assume, for

$$
t \leq \frac{4}{3} t_{H}
$$

It would be possible to analyze scenarios in which the center of the market is not served in duopoly equilibrium. But such cases would not involve exclusion, and we confine our attention to cases in which the market is covered in duopoly. ${ }^{21}$

The corresponding payoff per newspaper is

$$
\pi_{L L}^{d}=\frac{1}{2} t-F .
$$

We assume $F \leq \frac{1}{2} t$, which ensures that equilibrium duopoly profit per newspaper in the low- $t$ case if both newspapers are licensed is nonnegative. ${ }^{22}$ Duopoly equilibrium is illustrated in Figure 3.

\section{$5.2 \quad$ Neither newspaper licensed}

If neither newspaper is licensed, demands are scaled down by the factor $1-\mu$. The resulting payoff per newspaper is

$$
\pi_{U L, U L}^{d}=\frac{1}{2}(1-\mu) t-F .
$$

From (7), the reduction in profit of an unlicensed newspaper includes lost advertising revenue, a kind of loss unique to a newspaper that supplies a platform market.

\footnotetext{
${ }^{21}$ If one newspaper has an exclusive license to publish the complementary good, the assumption is that the submarket of readers who are indifferent to the complement is covered.

${ }^{22}$ This in turn implies that a licensed monopolist is profitable in the low- $t$ case.
} 


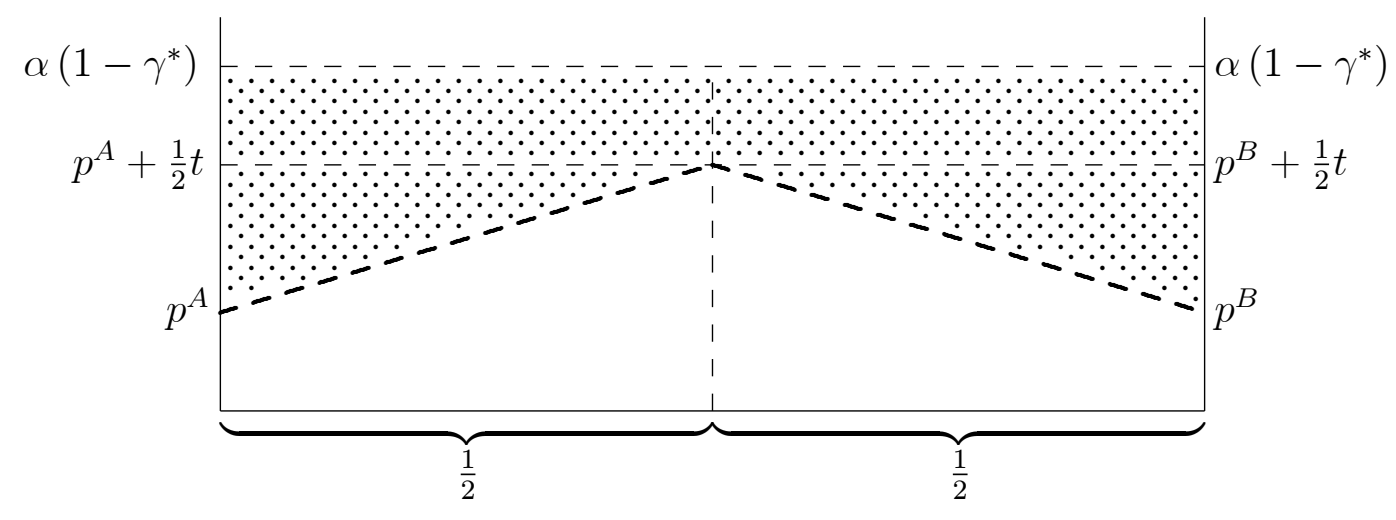

Figure 3: Duopoly equilibrium (no exclusive component or both newspapers licensed), market covered. Shaded area is consumer surplus. The horizontal axis shows location on the Hotelling line. The vertical axis shows delivered price.

\subsection{Duopoly: one newspaper licensed, one newspaper unlicensed}

Without loss of generality, suppose that newspaper A has a license for the essential complementary good, newspaper B does not.

\subsubsection{Low price (low $t)$}

Objective functions are given by (8), and the numbers of readers are

$$
n_{R}^{A}=\mu+(1-\mu)\left[\frac{1}{2}+\frac{\alpha\left(\gamma^{B}-\gamma^{A}\right)-p^{A}+p^{B}}{2 t}\right]
$$

and

$$
n_{R}^{B}=\frac{1}{2}(1-\mu)\left[1+\frac{\alpha\left(\gamma^{A}-\gamma^{B}\right)-p^{B}+p^{A}}{t}\right] .
$$

Economic profit per reader is given by (7). Equilibrium price per reader per advertisement is the bottleneck value for both newspapers, $\gamma^{A}=\gamma^{B}=\gamma^{*}$. 
Equilibrium prices $\operatorname{are}^{23}$

$$
\begin{aligned}
p^{A} & =\frac{4}{3} \frac{\mu}{1-\mu} t+t-\left[\left(1-\gamma^{*}\right)\left(\gamma^{*}-c\right)-f\right] \\
p^{B} & =\frac{2}{3} \frac{\mu}{1-\mu} t+t-\left[\left(1-\gamma^{*}\right)\left(\gamma^{*}-c\right)-f\right] .
\end{aligned}
$$

The consistency condition for the low-price solution to be valid is $p^{A} \leq$ $\alpha n_{a}^{A}-t$, and this is satisfied for

$$
t \leq \frac{1-\mu}{1-\frac{1}{3} \mu} t_{H} \equiv t_{L}
$$

\subsubsection{High price (high $t$ )}

In the high-price regime, newspaper A serves only a portion fraction of readers who regard the complementary good as essential. It divides the other group of consumers with newspaper B.

Newspaper B's first-order conditions are unchanged from the low- $p^{A}$ regime. Newspaper A's profit per reader is also as in the low- $p^{A}$ regime. Newspaper A's number of readers in the high- $p^{A}$ case is

$$
n_{R}^{A}=\mu \frac{\alpha\left(1-\gamma^{A}\right)-p^{A}}{t}+(1-\mu)\left[\frac{1}{2}+\frac{\alpha\left(\gamma^{B}-\gamma^{A}\right)-p^{A}+p^{B}}{2 t}\right] .
$$

Equilibrium readers' prices are

$$
\begin{aligned}
p^{A} & =\frac{4 \mu\left[\alpha\left(1-\gamma^{*}\right)-t\right]+(3+\mu)\left\{t-\left[\left(1-\gamma^{*}\right)\left(\gamma^{*}-c\right)-f\right]\right\}}{3+5 \mu} \\
p^{B} & =\frac{2 \mu\left[\alpha\left(1-\gamma^{*}\right)-t\right]+3(1+\mu)\left\{t-\left[\left(1-\gamma^{*}\right)\left(\gamma^{*}-c\right)-f\right]\right\}}{3+5 \mu} .
\end{aligned}
$$

\subsection{Consistency}

The consistency condition for the equilibrium price given by (26) to be in the high- $p^{A}$ case is

$$
p^{A} \geq \alpha\left(1-\gamma^{*}\right)-t
$$

\footnotetext{
${ }^{23}$ Nothing is gained by combining the terms in $t$ on the right in (22) and (23).
} 


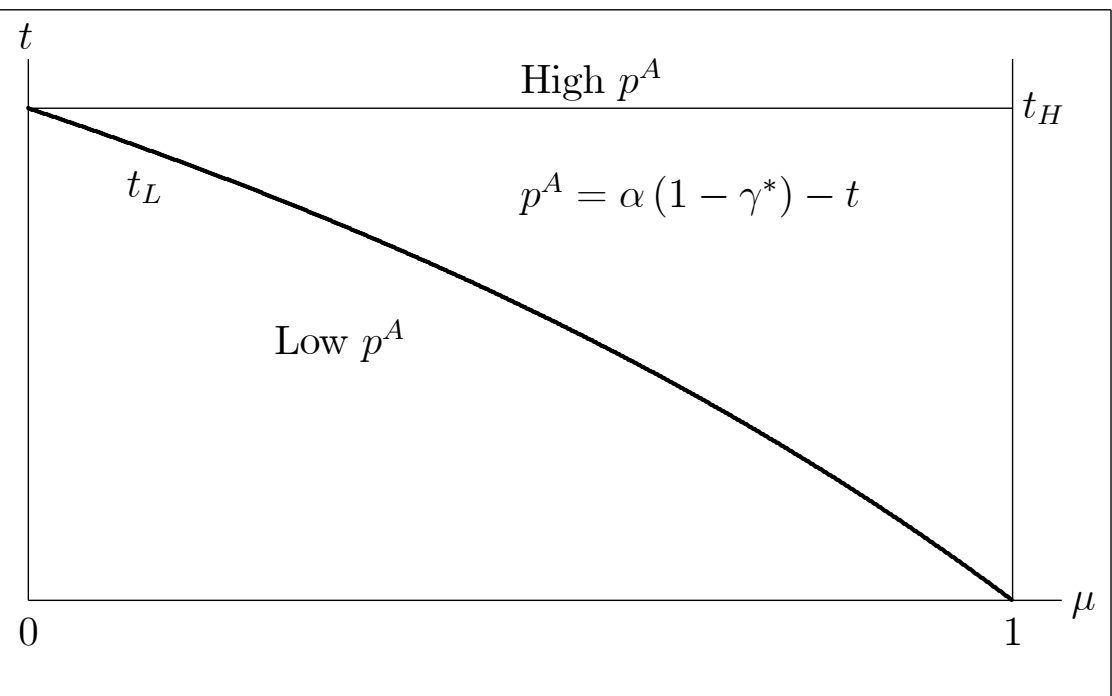

Figure 4: Pricing regimes, $(\mu, t)$-space, duopoly, newspaper A licensed, newspaper B not licensed.

After some manipulation, this becomes

$$
t \geq t_{H}
$$

The consistency condition for the low- $p^{A}$ regime, $(24)$, is $t \leq t_{L}$. In combination, we have three ranges relating $t$ to newspaper A's profit-maximizing price to readers,

$$
\begin{array}{cl}
t \leq t_{L} & p^{A} \leq \alpha\left(1-\gamma^{*}\right)-t \\
t_{L} \leq t \leq t_{H} & p^{A}=\alpha\left(1-\gamma^{*}\right)-t \\
t_{H} \leq t & p^{A} \geq \alpha\left(1-\gamma^{*}\right)-t
\end{array}
$$

\section{Intermediate product differentiation: $t_{L} \leq$ $t \leq t_{H}$}

For an intermediate degree of product differentiation, $t_{L} \leq t \leq t_{H}$, newspaper A sets $p^{A}$ to extract all surplus from the most distant readers who regard the complementary material as essential. The magnitude of $t_{H}-t_{L}$ increases with $\mu$ (see Figure 4). 


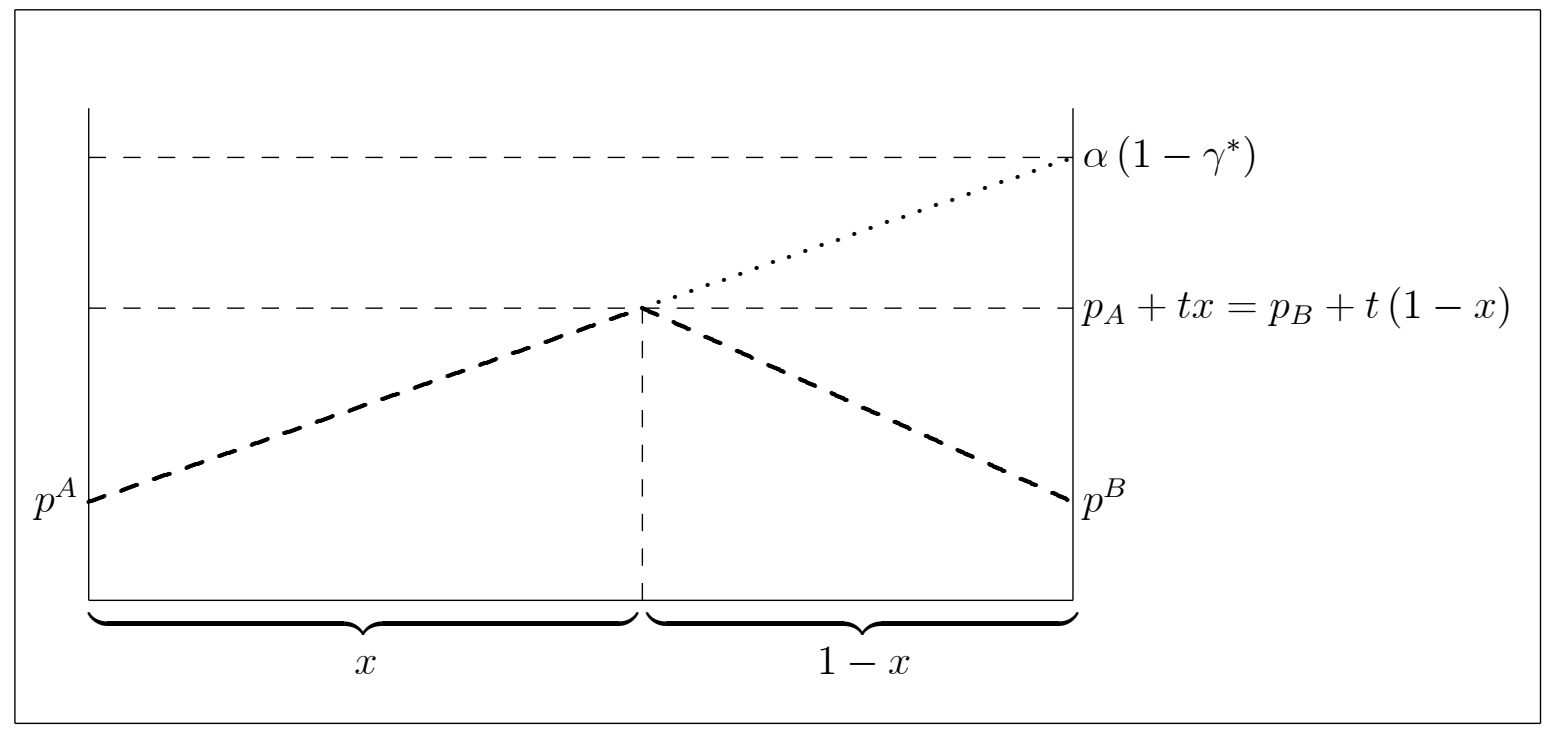

Figure 5: Duopoly, newspaper A licensed, newspaper B not licensed, intermediate- $t$ case. The horizontal axis shows location on the Hotelling line. The vertical axis shows delivered price.

The essential-complementary good submarket is covered. This case is shown in Figure 5. The elements of the intermediate- $t$ equilibrium are summarized here:

$$
\begin{gathered}
\gamma^{A}=\gamma^{B}=\gamma^{*} . \\
n_{a}^{A}=n_{a}^{B}=1-\gamma^{*} . \\
n_{R}^{A}=1-\frac{1}{2}(1-\mu) \frac{\alpha\left(1-\gamma^{*}\right)-p^{B}}{t} . \\
n_{R}^{B}=\frac{1}{2}(1-\mu) \frac{\alpha\left(1-\gamma^{*}\right)-p^{B}}{t} .
\end{gathered}
$$

In this case, $n_{R}^{A}+n_{R}^{B}=1$ and all readers are served. Further, $n_{R}^{A} \rightarrow 1$ and $n_{R}^{B} \rightarrow 0$ as $\mu \rightarrow 1$.

Knowing $p^{A}$, we obtain $p^{B}$ from newspaper B's reader-price first-order condition. Newspapers' equilibrium profits are

$$
\begin{gathered}
\pi_{L, U L}^{A}=\frac{2 t}{1+\mu}\left[1-\frac{1}{2}(1-\mu) \frac{t_{H}}{t}\right]^{2}-F \\
\pi_{L, U L}^{B}=\frac{1}{2}(1-\mu) \frac{t_{H}^{2}}{t}-F .
\end{gathered}
$$




\subsection{License offer games}

For the syndicate, the license offer game is an optimal control problem: it decides which of two games the newspapers play. The syndicate may make a take-it-or-leave-it offer of a license only to newspaper A (without loss of generality) at a contingent fee $\left(L_{A}^{1}, L_{A}^{2}\right)$, where $L_{A}^{1}$ is the fee if newspaper $\mathrm{B}$ does not enter and $L_{A}^{2}$ is the fee if newspaper B does enter. Alternatively, the syndicate may make take-it-or-leave-it offers to both newspapers at contingent fee $\left(L_{A B}^{1}, L_{A B}^{2}, L_{A B}^{3}\right)$, where $L_{A B}^{1}$ is the fee paid by one newspaper if the other newspaper does not enter, $L_{A B}^{2}$ is the license fee paid by one newspaper if the other newspaper accepts the offer and enters, and $L_{A B}^{3}$ is the license fee if the other newspaper rejects the offer and enters. In all cases, equilibrium license fees leaves each newspaper a small positive payoff if the offer is accepted. ${ }^{24}$

If the syndicate offers a license only to newspaper A, A and B play the game shown in Figure 6. Newspaper A may either accept the offer of an exclusive license and enter the market, reject the offer and enter the market, or stay out. The game then moves to one of newspaper B's decision nodes. At each node, B's choices are to enter the market without a license or to stay out of the market.

If the syndicate offers a license to both newspapers, A and B play the game shown in Figure 8. Newspapers simultaneously decide to accept the offer of a license and enter the market, to reject the offer and enter the market, or to stay out.

\subsubsection{Syndicate offers a license only to newspaper A}

It is reasonable to assume that if the Syndicate offers a license to newspaper A, newspaper B would be aware of the offer and A's response when it makes its entry decision. Thus the path of decisions (Figure 6) is sequential.

\footnotetext{
${ }^{24}$ In equilibrium, it is $L_{A}^{1}$ that is paid in the first game, $L_{A B}^{2}$ that is paid in the second game. The other license fees maximize the syndicate's payoff off the equilibrium path. If the syndicate specifies license fee $L_{A}^{1}$ for all states of the world in the first game, and license fee $L_{A B}^{2}$ for all states of the world in the second game, Nash equilibrium outcomes are as indicated in the text.
} 


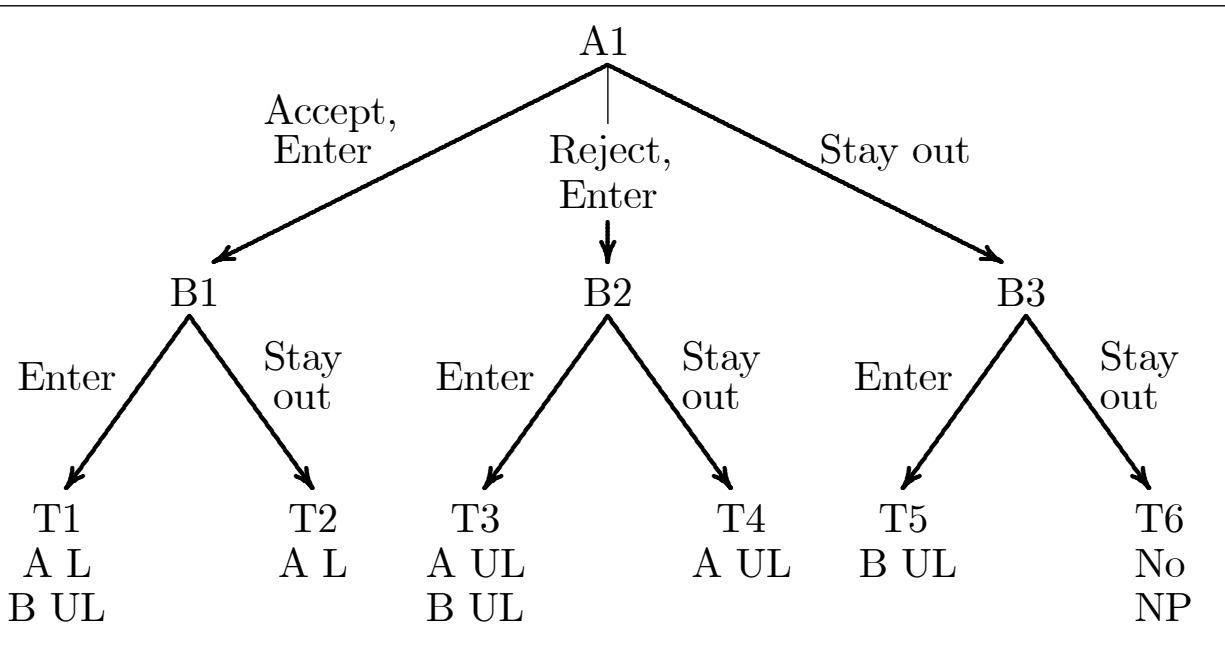

Figure 6: Outcomes of A, B game if syndicate offers an exclusive license to A. "L" denotes licensed, "UL" denotes unlicensed.

License fees If newspaper A accepts an offer of an exclusive license, B's payoff as an unlicensed duopolist, $\pi_{L, U L}^{B}$, is negative for $\mu$ sufficiently large:

$$
\mu>1-\frac{2 t F}{t_{H}^{2}} \equiv \mu_{X}
$$

For such $\mu$, if newspaper A accepts an offer of an exclusive license, it generates economic profit

$$
\pi_{L}^{m}=2 t_{H}-t-F
$$

If the syndicate makes a take-it-or-leave-it offer of an exclusive license to A, to ensure that $\mathrm{A}$ will accept, it will set a license fee that in equilibrium leaves newspaper A a small positive economic profit if it accepts the license and newspaper $\mathrm{B}$ does not enter:

$$
L_{A}^{1}=\pi_{L}^{m}-\varepsilon
$$

for $\varepsilon$ positive and small.

If newspaper B enters without a license, newspaper A's payoff is (30). The contingent license fee that maximizes the syndicate's payoff in this outof-equilibrium state of the world is

$$
L_{A}^{2}=\pi_{L, U L}^{A}-\varepsilon .
$$


If $\mathrm{A}$ accepts the offer and B stays out, A makes a small positive economic profit, $\mathrm{B}$ makes zero economic profit. If $\mathrm{A}$ accepts the offer and $\mathrm{B}$ enters, $\mathrm{B}$ makes losses for $\mu$ sufficiently large. If $\mathrm{A}$ rejects the offer and both newspapers enter in the market, the two newspapers are a duopoly serving a market of $1-\mu$ readers. Duopoly profits per newspaper, (19), are negative for

$$
\mu>1-\frac{2 F}{t} \equiv \mu_{U L, U L} .
$$

We have assumed $\mu>\mu_{X}$, and this implies $\mu>\mu_{U L, U L}$. Hence if A rejects the license offer and both newspapers enter, both newspapers make economic losses.

If A rejects the offer of an exclusive license and enters, while B stays out, A's economic profit as an unlicensed monopolist (see Table 1) is negative for

$$
\mu>1-\frac{F}{2 t_{H}-t} \equiv \mu_{U L}^{m} .
$$

Assume

$$
\mu>\max \left(\mu_{X}, \mu_{U L}^{m}\right) .
$$

Under this assumption, if $\mathrm{A}$ rejects the offer of an exclusive license and enters, while B stays out, then A makes economic losses and B makes zero economic profit.

If A stays out, and B enters, A earns zero economic profit. B is an unlicensed monopolist. The assumption $\mu>\max \left(\mu_{X}, \mu_{U L}^{m}\right)$ implies that B makes economic losses.

If the syndicate offers a license only to newspaper A, the newspapers play the game shown in Figure 6. Figure 7 shows the payoff matrix for the resulting finite game of complete and perfect information. The signs shown in the figure are valid for $\mu>\max \left(\mu_{X}, \mu_{U L}^{m}\right)$.

(Accept and enter, Stay out) is the unique noncooperative equilibrium of the game. The syndicate's payoff is

$$
L_{A}^{1}=\pi_{L}^{m}-\varepsilon=2 t_{H}-t-F-\varepsilon,
$$

for $\varepsilon$ small.

\subsubsection{Syndicate offers licenses to $\mathrm{A}$ and $\mathrm{B}$}

License fee If the syndicate makes simultaneous offers of licenses to both newspapers, newspaper decisions are simultaneous, and newspapers play the 


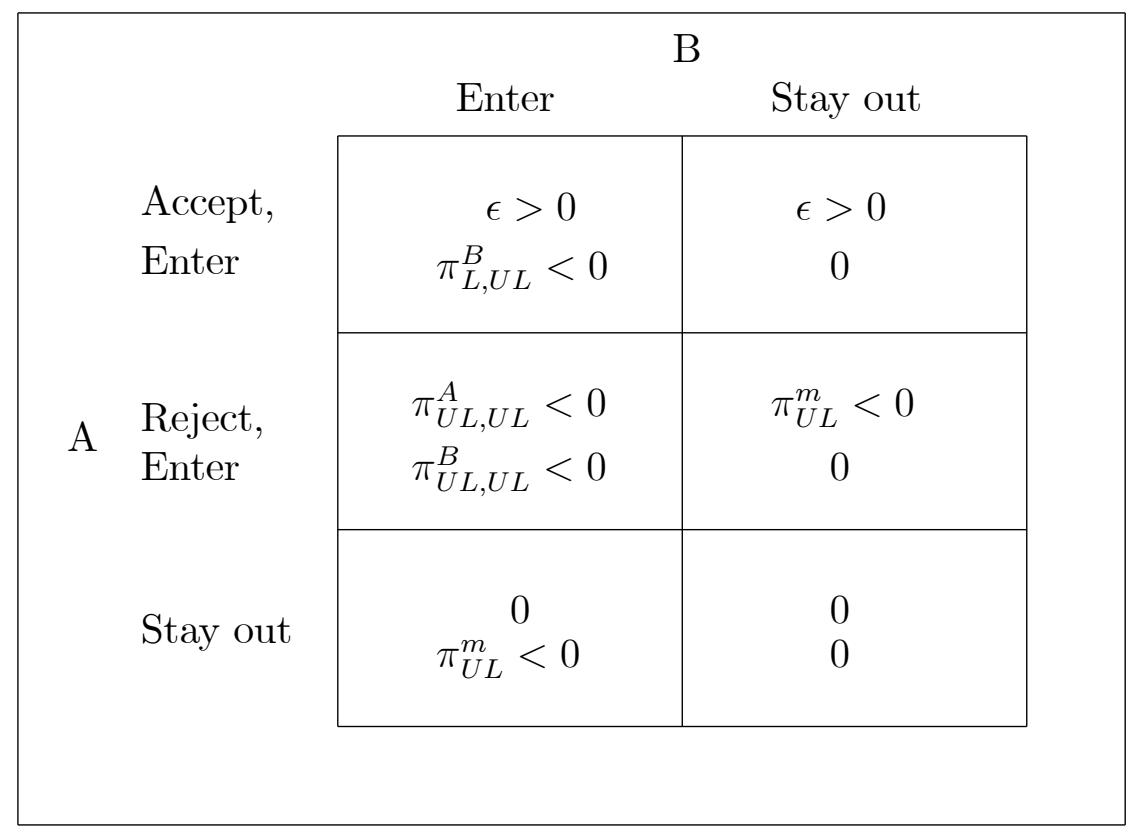

Figure 7: Payoff matrix for newspaper game if syndicate offers an exclusive license to newspaper A. Upper element is A's payoff, lower element is B's payoff. Signs given are for $\mu$ sufficiently large; see text for discussion. 


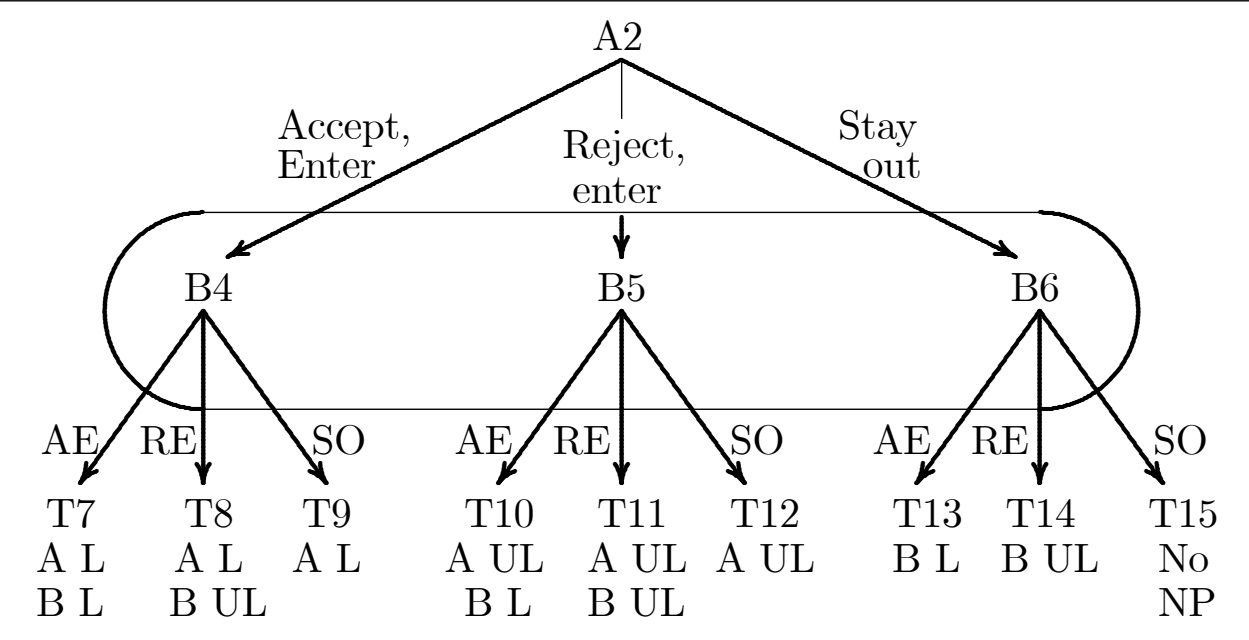

Figure 8: Outcomes of A, B game if syndicate offers licenses to both newspapers. "L" denotes licensed, "UL" denotes unlicensed.

game shown Figure 8. With contingent license fees

$$
\begin{gathered}
L_{A B}^{1}=\pi_{L}^{m}-\varepsilon \\
L_{A B}^{2}=\pi_{L L}^{d}-\varepsilon \\
L_{A B}^{3}=\pi_{L, U L}^{d}-\varepsilon,
\end{gathered}
$$

a newspaper that accepts the offer earns payoff $\varepsilon>0$ whatever the decision of the other newspaper, makes losses if it rejects and enters, for $\mu$ sufficiently large, and breaks even if it stays out.

Figure 9 shows the payoff matrix for the game played by A and B if the syndicate offers licenses to both newspapers. The signs shown in the figure are valid for $\mu>\max \left(\mu_{X}, \mu_{U L}^{m}\right)$. The unique noncooperative equilibrium of the game is (Accept and enter, Accept and enter). The syndicate's payoff is

$$
2 L_{A B}=\pi_{L, L}^{A}-\varepsilon+\pi_{L, L}^{B}-\varepsilon=2\left(\frac{1}{2} t-F-\varepsilon\right) .
$$




\begin{tabular}{|c|c|c|c|c|}
\hline & & $\begin{array}{l}\text { Accept } \\
\text { Enter }\end{array}$ & $\begin{array}{c}\text { B } \\
\text { Reject, } \\
\text { Enter }\end{array}$ & Stay out \\
\hline & $\begin{array}{l}\text { Accept, } \\
\text { Enter }\end{array}$ & $\begin{array}{l}\varepsilon>0 \\
\varepsilon>0\end{array}$ & $\begin{array}{c}\varepsilon>0 \\
\pi_{L, U L}^{B}<0\end{array}$ & $\begin{array}{c}\varepsilon>0 \\
0\end{array}$ \\
\hline A & $\begin{array}{l}\text { Reject, } \\
\text { Enter }\end{array}$ & $\begin{array}{c}\pi_{U L, L}^{A}<0 \\
\varepsilon>0\end{array}$ & $\begin{array}{l}\pi_{U L, U L}^{A}<0 \\
\pi_{U L, U L}^{B}<0\end{array}$ & $\begin{array}{c}\pi_{U L}^{m}<0 \\
0\end{array}$ \\
\hline & $\begin{array}{l}\text { Reject, } \\
\text { Stay out }\end{array}$ & $\begin{array}{c}0 \\
\varepsilon>0\end{array}$ & $\pi_{U L}^{m}<0$ & $\begin{array}{l}0 \\
0\end{array}$ \\
\hline
\end{tabular}

Figure 9: Payoff matrix for newspaper game if syndicate offers a license to both newspapers. Upper element is A's payoff, lower element is B's payoff. Signs given are for $\mu$ sufficiently large; see text for discussion.

\subsubsection{Syndicate's payoff}

The difference between the syndicate's payoff if it offers an exclusive license and if it offers both newspapers licenses is

$$
\begin{gathered}
L_{A}-2 L_{A B}=\pi_{L}^{m}-\left(\pi_{L, L}^{A}+\pi_{L, L}^{B}\right)+\varepsilon \\
=2\left(t_{H}-t\right)+\varepsilon>0 .
\end{gathered}
$$

This implies

Theorem 1 For intermediate values of $t\left(t_{L} \leq t \leq t_{H}\right)$ and $\mu$ sufficiently large,

(a) the syndicate's payoff-maximizing choice is to make a take-it-or-leave-it offer of an exclusive license to one of the two newspapers, at license fee $L_{A}=$ $\pi_{L}^{m}$

(b) the payoff-maximizing choice of the newspaper that is offered a license is to accept 


\begin{tabular}{|l|c|c|c|}
\hline & Licensed Monopoly & Licensed Duopoly & Duopoly - Monopoly \\
\hline $\begin{array}{l}\text { Newspaper } \\
\text { profit }\end{array}$ & $2 t_{H}-t-F$ & $t-2 F$ & $-2\left(t_{H}-t\right)-F<0$ \\
\hline $\begin{array}{l}\text { Advertiser } \\
\text { profit }\end{array}$ & $\frac{1}{2}\left(1-\gamma^{*}\right)^{2}$ & $\frac{1}{2}\left(1-\gamma^{*}\right)^{2}$ & 0 \\
\hline $\begin{array}{l}\text { Consumer } \\
\text { Surplus }\end{array}$ & $\frac{1}{2} t$ & $2\left(t_{H}-t\right)+\frac{3}{4} t$ & $2\left(t_{H}-t\right)+\frac{1}{4} t>0$ \\
\hline $\begin{array}{l}\text { Net Sur- } \\
\text { plus }\end{array}$ & $2 t_{H}-\frac{1}{2} t-F+\frac{1}{2}\left(1-\gamma^{*}\right)^{2}$ & $2 t_{H}-\frac{1}{4} t-2 F+\frac{1}{2}\left(1-\gamma^{*}\right)^{2}$ & $\frac{1}{4} t-F$ \\
\hline
\end{tabular}

Table 2: Welfare Comparison, Intermediate-t.

(c) the payoff-maximizing choice of the newspaper that is not offered a license is to stay out of the market.

For $\mu$ sufficiently close to 1 , the syndicate maximizes its payoff by making a take-it-or-leave-it offer of an exclusive license to one of the two newspapers, at license fee $L_{A}=\pi_{L}^{m}-\varepsilon$. For intermediate degrees of product differentiation, an exclusive license for a complementary good that a sufficient number of consumers regard as essential can make the unlicensed newspaper unprofitable, although both newspapers would be profitable if both were licensed.

\subsubsection{Welfare}

Table 2 compares profits, consumer surplus, and net surplus under licensed monopoly and licensed duopoly for the intermediate- $t$ case. ${ }^{25}$ The "newspaper profit" given in the first row of the table is the total profit generated by the operation of active newspapers. ${ }^{26}$ Comparing licensed duopoly and licensed monopoly shows that monopoly profit is greater than total duopoly profit, and duopoly consumer surplus is greater than monopoly consumer surplus. Advertisers' profit is the same under both regimes, since the market is covered in both cases. The difference in net surplus under the two

\footnotetext{
${ }^{25}$ We do not enter into the debate over the Kaldor-Hicks hypothetical compensation principle, which leads to use of net surplus as a welfare measure, and Lionel Robbins' view that the components of net surplus should be examined separately, the terms of which are well known (see Chipman and Moore, 1978).

${ }^{26}$ The license fee determines the division of this surplus between newspaper and syndicate, but does not affect the amount of the surplus.
} 
regimes is

$$
N S^{d}-N S^{m}=\frac{1}{4} t-F
$$

We have assumed that licensed duopoly is profitable for both newspapers, $\frac{1}{2} t-F \geq 0$. Then $N S^{d} \geq N S^{m}$ for $F \leq \frac{1}{4} t, N S^{d}<N S^{m}$ for $\frac{1}{4} t<F \leq \frac{1}{2} t$. If fixed cost is small relative to reader preferences, duopoly net surplus exceeds monopoly net surplus, and vice versa.

\section{Low product differentiation, high product differentiation $^{27}$}

In Section 6 we considered the case of intermediate product differentiation, $t_{L} \leq t \leq t_{H}$. Here we indicate briefly results if differentiation is low, $t \leq t_{L}$, or if differentiation is high, $t>t_{H}$.

\subsection{Low product differentiation}

If newspapers are close substitutes, an example shows that an exclusive license need not be exclusionary.

The inequality that defines the low-t region is (24),

$$
t \leq \frac{1-\mu}{1-\frac{1}{3} \mu} t_{H}=t_{L} .
$$

Let parameter values be $\alpha=0.9001, c=f=0.00001, F=0.01$, and $\mu=0.8$. Then $t_{L}=0.1231$. If $t=0.1$, B's payoff is $\pi_{L, U L}^{B, \text { low }}{ }^{t}=0.1244>0$. For any $\mu$, if $t$ is sufficiently small - if products are close enough to being perfect substitutes, the unlicensed newspaper has positive profit.

With low differentiation, B's share of readers falls as $\mu$ rises, but is bounded away from 0 . As A's share of readers rises, it increases $p^{A}$. As one expects for price-setting duopoly, as A sets a higher price, so does B. The net effect of falling $n_{R}^{B}$ and rising $p^{B}$ as $\mu$ rises is that B's profit $\pi_{L, U L}^{B}$ rises as $\mu$ rises.

\footnotetext{
${ }^{27}$ Full details of the two cases considered in this section are given in the derivations document mentioned in footnote 4 .
} 


\subsection{High product differentiation}

For

$$
t_{H} \leq t \leq \frac{4}{3} t_{H}
$$

newspaper A sets a high-enough price that some of the essential-complementary good submarket is uncovered, while the segment of the market that is indifferent toward the complementary good is covered (see (18)).

From Table 1, licensed monopoly economic profit is

$$
\pi_{\text {high } t}^{m}=\frac{t_{H}^{2}}{t}-F
$$

and if the syndicate offers an exclusive license, it will set license fee

$$
L_{A}^{\text {hight }}=\pi_{\text {high } t}^{m}-\varepsilon
$$

for the equilibrium case that $\mathrm{A}$ accepts the offer of an exclusive license and B stays out.

If the monopolist is unlicensed, its payoff $\pi_{h i g h t}^{m, U L}=(1-\mu) \frac{t_{H}^{2}}{t}-F$ is negative for $\mu$ sufficiently large,

$$
\mu>1-\frac{t F}{t_{H}^{2}}=\mu_{U L}^{m, h i g h t} .
$$

Duopoly payoffs if both newspapers are licensed or if neither newspaper is licensed are unchanged from the previous cases. If the syndicate offers licenses to both newspapers, it will set contingent license fees to extract all but a small amount of surplus at alternative terminal nodes of the game tree; this is

$$
L_{A B}^{\text {high } t}=\frac{1}{2} t-F-\varepsilon
$$

for the case that both newspapers accept the offer. This leads to a game with noncooperative equilibrium (Accept and enter, Accept and enter), for $\mu$ sufficiently large.

If the syndicate offers $\mathrm{A}$ an exclusive license at appropriately structured contingent license fees, the newspapers play a game with equilibrium (Accept and enter, Stay out), for $\mu$ sufficiently large. In this sense, an exclusive license can be exclusionary. 
The difference between the syndicate's equilibrium payoff in the two cases is

$$
2 L_{A B}^{\text {high } t}-L_{A}^{\text {high } t}=\frac{t^{2}-t_{H}^{2}}{t}-F-\varepsilon
$$

and this is of ambiguous sign. In the high- $t$ licensed monopoly regime, the market is uncovered. With licensed duopoly, the market is covered. For small $F$ and $t-t_{H}$ sufficiently large, the syndicate's payoff harvesting duopoly profit in a covered market can exceed its payoff from an uncovered monopoly market.

An exclusive license can make the unlicensed newspaper unprofitable. But if product differentiation is sufficiently great, a large-enough number of readers would then be unserved that the syndicate's most profitable option is to offer licenses to both newspapers.

\section{Conclusion}

The literature on one-sided markets (for example, Whinston (1990)) suggests that tying, bundling, and exclusive dealing contracts may, but need not, have exclusionary effect. Our results extend this finding to exclusive licenses in two-sided markets. In such markets, the exclusionary impact of a loss of patronage from one side of the market (readers) is magnified by the resulting loss in revenue (advertising) from the other side of the market, for intermediate degrees of product differentiation.

Many regional markets - regional in physical space, regional in productcharacteristic space — will support at most a small number of firms. In such markets, an exclusive contract for a complementary product can make unlicensed firms unprofitable. Such exclusion makes consumers worse off, and if consumer preferences are sufficiently strong, reduces net surplus.

Our results hold for the case of a monopoly upstream supplier of an essential complementary good. A logical extension of this framework, and a subject for possible future research, is to an upstream duopoly of verticallydifferentiated components. It is natural to expect that exclusive licenses will be exclusionary if upstream components differ sharply in quality, otherwise not. One might also view press syndicates as platforms that allow advice columnists, astrologers, and comic strip artists to interact with newspapers. Also a subject for future research, this would lead to a model of an upstream platform market supplying a downstream platform market. 


\section{References}

Argentesi, E. (2004). "Demand estimation for Italian newspapers: the impact of weekly supplements" Working Paper of the European University Institute, 2004/28.

Armstrong, M. (2006). "Competition in two-sided markets" Rand Journal of Economics 37:668-691.

Bucklin, R. E., Caves, R. E. and Lo, A. W. (1989). "Games of survival in the US newspaper industry" Applied Economics 21, 631-649.

Chipman, J. S. and Moore, J. C. (1978). "The new welfare economics 1939-1974" International Economic Review 19:547-584.

Church, J., and Gandal, N. (2005). "Platform competition in telecommunications," in M. Cave, S. Majumdar, I. Vogelsang (Eds.), Technology evolution and the Internet, The Handbook of Telecommunications Economics, vol. 2, North-Holland, Amsterdam.

Dewenter, R. (2003). "Media Markets with Habit Formation" University of the Federal Armed Forces Hamburg. Economics Discussion Paper No. 5.

Doganoglu, T. and Wright, J. (2010). "Exclusive dealing with network effects" International Journal of Industrial Organization 28:145-154.

Gelsanliter, D. (1995). Fresh Ink: Behind the Scenes of a Major Metropolitan Newspaper. University of North Texas Press, Denton, Texas.

Genesove, D. (2003). "Why are there so few (and fewer and fewer) two newspaper towns ?", Mimeo.

Hagiu, A., and Lee, R. S. (2011). "Exclusivity and control" Journal of Economics \& Management Strategy 20:679-708.

Hogendorn, C., and Yuen, K. Y. (2009) "Platform competition with 'must-have' components," Journal of Industrial Economics 57:294-318.

Kind, H. J., Nilssen, T., and Sørgard, L. (2007). "Competition for Viewers and Advertisers in a TV Oligopoly." Journal of Media Economics 20:211233.

Lee, R. S. (2013). "Vertical Integration and Exclusivity in Platform and Two-Sided Markets" American Economic Review 103:2960-3000.

Rey, P. and Tirole, J. (2007). "A primer on foreclosure," Chapter 33 in Mark Armstrong and R. Porter, editors Handbook of Industrial Organization, Volume 3. Elsevier B.V., pp. 2145-2220.

Rochet, J. C., and Tirole, J. (2006). "Two-sided markets: a progress report" Rand Journal of Economics 37:645-667. 
Rosse, J. N. (1970). "Estimating cost function parameters without using cost data: illustrated methodology" Econometrica 38:256-275.

Rysman, M. (2007). "An empirical analysis of payment card usage" Journal of Industrial Economics 55:1-36.

- (2009). "The economics of two-sided markets" Journal of Economic Perspectives 23(3), 125-143.

Shapiro, C. (1999). "Exclusivity in network industries" George Mason Law Review 7:673-683.

Stennek, J. (2014). "Exclusive quality: why exclusive distribution may benefit the TV viewers" Information Economics and Policy 26:42-57.

Strömberg, D. (2004). "Mass media competition, political competition, and public policy" Review of Economic Studies 71:265-284.

Viecens, M. F. (2009). "Pricing strategies in two-sided platforms: the role of sellers' competition" FEDEA Working Paper 2009-11.

Weeds, H. (2015). "TV wars: exclusive content and platform competition in pay TV" Economic Journal (forthcoming).

Whinston, M. (1990). "Tying, foreclosure, and exclusion" American Economic Review 80:837-859.

- (2006). Lectures on Antitrust Economics. Cambridge, Massachusetts and London, England: MIT Press. 